\title{
CORRIGENDUM
}

\section{Associations of socioeconomic factors with inadequate dietary intake in food aid users in France (The ABENA study 2004-2005)}

C Méjean, V Deschamps, C Bellin-Lestienne, A Oleko, N Darmon, S Hercberg and K Castetbon European Journal of Clinical Nutrition (2010) 64, 440; doi:10.1038/ejcn.2010.12

Correction to: European Journal of Clinical Nutrition (2010) 64; doi:10.1038/ejcn.2009.153

Since the publication of this paper, the authors have noticed that two of the author names were incorrectly listed as $\mathrm{H}$ Serge and $\mathrm{C}$ Katia. The correct names are shown above.

The authors apologize for any inconvenience caused. 